\title{
The effectiveness of irrigation method by normal saline compared to povidone iodine soaking in decreasing the rate of contamination in appendectomy wound
}

\author{
Hassan A. Hassan* \\ Mohannad K.Al-Bermani** \\ Aws B. Abed*
}

\author{
FRCS \\ FICS \\ FICS
}

\begin{abstract}
:
Fac Med Baghdad

2016; Vol.58, No.3

Received:April,2016

Accepted:June. 2016

Background: The number of bacteria is important as much as the type of it in developing wound infection. Pressurized irrigation of the surgical wound leads to decrease bacterial number which led to decrease incidence of wound infection.

Objective: to evaluate effectiveness of normal saline irrigation and povidone iodine soaking in decreasing the number of bacteria.

Patient and method: This was a prospective study of 100 patients who were admitted to Al Kadhimyia Teaching Hospital during the period from May 2012 and April 2013 with diagnosis of acute appendicitis. After appendicectomy was done, patients were randomized into two groups, fifty patients (group one) the subcutaneous tissue was irrigated by $200 \mathrm{ml}$ normal saline. The subcutaneous tissue of the other fifty patients (group two) was soaked by 10 percent povidone iodine solution. Swabs were taken from subcutaneous tissue before and after irrigation or soaking in both groups. All swabs were implanted in special type of agars. The number of colonies appeared represents the number of bacteria that grow under the incubation conditions employed.

Results: there was a significant reduction in the number of bacterial colonies in group I; compared to group II.

Conclusion: Irrigation of the subcutaneous tissue with normal saline is an effective method in decreasing the rate of bacterial contamination when compared to the use of povidone iodine soaking.

Keywords: Normal saline, povidone iodine, irrigation, wound infection, contamination, bacteria.
\end{abstract}

Introduction:

Wound infection is defined as the invasion of organisms through tissue following a breakdown of local and systemic host defense which lead to cellulites, lymphangitis, abscess and bacteremia (1).It is particularly common after prolonged intra-abdominal surgeries and it is a major factor that postpones wound healing $(2,3,4)$.

Surgical site infection (SSI) represents $15 \%$ of all nosocomial infections, which lead to increased length of postoperative hospital stay, drastically escalated expense, higher rates of hospital readmission and jeopardized health outcomes. It's also a major cause of morbidity in surgical patients. $(5,6)$

The prevention of surgical site infections encompasses meticulous operative technique, timely administration of appropriate preoperative antibiotics, and a variety of preventive measures aimed at neutralizing the threat of bacterial, viral and fungal contamination posed by operative staff, the operating room environment, and the patient's endogenous skin flora. In the majority of SSI cases, the pathogen source is the native

\footnotetext{
* Kadhimyia Teaching Hospital.

**Coresponding Auther: Baghadad Teaching Hospital. muhsurg@yahoo.com
}

flora of the patient's skin, mucous membranes, or hollow viscera $(5,6)$

A variety of cleansing solutions exists, and their selection should be based on their cleansing effectiveness, lack of cytotoxicity and cost. Many cleansing solutions have been demonstrated safe and effective, whereas others may damage and destroy cells essential to the healing process. 7

There are different cleansing methods in order to decrease or kill microorganism which were tested all over the world, their use depend on availability, feasibility and effectiveness.

Application of especial solutions or washing the wounds with them will be helpful to prevent infection. These include: tap water, normal saline, procaine spirit, distilled water, acetic acid $(25 \%)$, povidone-iodine, hydrogen peroxide $(3 \%)$ and others ( 8-13).

Equipment used for irrigation includes bulb syringes, piston syringes, pressure canisters, whirlpool agitator, and whirlpool hose sprayer, irrigation fluid in plastic containers with a pour cap or nozzle, and pulsed lavage (e.g., jet lavage, mechanical lavage, pulsatile lavage, mechanical irrigation, and highpressure irrigation). Prophylactic intra-operative wound 
irrigation before skin closure has been proposed to reduce bacterial wound and the surrounding skin contamination to the level that can be managed by host defenses and the risk of SSI14, 15, 16.

\section{Patients and Methods:}

To study the effectiveness of normal saline irrigation and povidone iodine soaking to the subcutaneous tissue in decreasing the chance of wound contamination, a prospective randomized clinical trial was conducted at department of surgery in Al-Kadhimiya Teaching Hospital between May 2012 and April 2013.

Hundred patients with complicated appendicitis were included in this prospective study. The inclusion criteria were adults and children of both sexes admitted with clinical diagnosis suggestive of acute appendicitis. Pregnant women and patients with immune deficiency (diabetes mellitus, uremics and those on chemotherapy) were excluded.

The study was restricted to patients with surgeries extending up to one hour which considered being prolonged surgeries, which itself associated with higher risk of infection. All appendicectomies were performed by resident surgical team with simple double ligature to the stump through a classical right grid iron incision of about $7-10 \mathrm{~cm}$

At the end of surgery, and before closure of the skin, patients were randomized into two groups, fifty patients (group one) the subcutaneous tissue was irrigated by $200 \mathrm{ml}$ normal saline applied under hand pressure using 19 gauge syringe. The subcutaneous tissue of the other fifty patients (group two) was soaked by 10 percent povidone iodine solution for five minutes.

Swabs were taken from subcutaneous tissue before and after irrigation with normal saline in group one. Also swabs were taken from subcutaneous tissue in group two before and after soaking with povidone iodine solution.

All swabs were implanted in special type of agars called brain heart agar in which most types of bacteria grow. These agars were incubated for two days at $37^{\circ} \mathrm{C}$. The numbers of bacterial colonies in this study were calculated through standard plate count method which is an indirect measurement of cell density and reveals information related only to live bacteria.

The assumption is that, each viable bacterial cell is separate from others (as the swabs were spread well) will develop into single discrete colony, thus the number of colonies should give the number of bacteria that can grow under the incubation conditions employed.

\section{Results:}

Group 1, included 50 patients (22 females, 28 males), the subcutaneous tissue was irrigated with normal saline.

Group 2 included 50 patients, (24 females and 26 males) the subcutaneous tissue was soaked with povidone iodine.

Age of the patients in group 1 ranged between 7-41 with mean of 26.5year while in group 2 age ranged between 8- 37 with mean of 24.5 year.

Operation time ranged in both groups between 25-90 minutes the average was 1 hour in both groups

The number of bacterial colonies before irrigation of subcutaneous tissue with normal saline (group 1) ranged between 10-250 mean 100.36 while the number of bacterial colonies after irrigation ranged between $0-72$ colonies mean 16.32. There was a significant reduction in the number of bacterial colonies after normal saline irrigation (group1); p-value was less than 0.05 as shown in table.

The number of bacterial colonies before soaking of subcutaneous tissue with povidone iodine (group2) ranged between 6-250 mean 134.22. While after soaking, the number of bacterial colonies ranged between 1-250 colonies mean 109.62.There was no significant reduction in the number of bacterial colonies after soaking the subcutaneous tissue with povidone iodine (group 2); p value was more than 0.05 as shown in table.

Table (1): The number of cases treated with both normal saline \& povidone iodine with its mean, mean of difference, standard deviation and $p$ value.

\begin{tabular}{|c|c|c|c|c|c|c|c|c|}
\hline Substance & $\begin{array}{l}\text { No. of } \\
\text { cases }\end{array}$ & $\begin{array}{c}\text { Range of number } \\
\text { of colonies before } \\
\text { treatment }\end{array}$ & $\begin{array}{c}\text { Mean of number } \\
\text { of colonies before } \\
\text { treatment }\end{array}$ & $\begin{array}{c}\text { Range of number } \\
\text { of colonies after } \\
\text { treatment }\end{array}$ & $\begin{array}{l}\text { Mean of number } \\
\text { of colonies after } \\
\text { treatment }\end{array}$ & $\begin{array}{l}\text { Mean of } \\
\text { difference }\end{array}$ & $\begin{array}{c}\text { Standard } \\
\text { deviation of } \\
\text { difference }\end{array}$ & P value \\
\hline Normal saline & 50 & $10-250$ & 100.36 & $0-72$ & 16.32 & 84.82 & 65.741 & $<0.0002$ \\
\hline Povidone iodine & 50 & $6-250$ & 134.22 & $1-250$ & 169.62 & 24.56 & 6.0963 & 0.146 \\
\hline
\end{tabular}




\section{Discussion:}

In this study we try to compare two methods and substances that may assist in decreasing the rate of contamination in the surgical wound so as to decrease the incidence of wound infection. As appendectomy is the commonest surgery in surgical practice and its one of the most common causes of mortality, despite medical advances, it continues to be a major problem. We choose to do our study on its wound specially that nearly most surgical personnel are quite familiar with its common complications such as wound infections. $(17,18)$

Most of studies that deals with this subject depend on clinical features of wound infection in 3rd, 5th, and 7th day post operatively to detect effectiveness of cleansing methods and cleansing solution .but in our study we prefer to calculate the number of microorganism in the wound before and after cleansing, because we think that this method is more accurate for evaluating the effectiveness of cleansing methods and solutions. The risk factors for development of wound infection (Like preoperative shaving, hand washing and all technical precautions of surgery and wound closure) were the same and controlled in both groups except the wound cleaning method and solution. ComillaSasson et al 19 comparing wound healing outcomes and infection rates in wounds cleaned with water and those cleaned with normal saline. Trials involved patients of all ages with a wound of any etiology and in any setting were included. Trials were excluded if they involved dental procedures or burns. He found out that Normal saline is most often preferred as it is relatively inexpensive, nontoxic to tissues, and does not affect normal skin flora. The use of tap water to cleanse wounds has also been examined. The Authors conclude that there is insufficient evidence to either support or refute the claim that tap water is comparable or superior to normal saline. This result reflect the action of irrigation method, regardless the substance. Regarding the effectiveness of choosing normal saline itself in irrigation method our result was similar to the results of Cunliffe, P.J. and Ovington, L.G in that sterile normal saline regarded as the most appropriate and preferred cleansing solution, because it is nontoxic, isotonic solution that does not damage healing tissues.20,21. Patel CV et al.22 who used copious irrigation ( 1 - 1.5 liter) saline to facilitate local dilution of the organism load which lift bacteria and debris from the wound .The majority of uncomplicated (eg, superficial-incisional) SSIs do not require any further technique. The results of IrajFeizi ;IrajPoorfarzan and BitaShahbazzadegan17showed that (aggressive washing method with (1 - 1.5 liter) normal saline by pressure is also an effective technique in patients with perforated appendicitis and wound infection. The same method of using syringe irrigation, Stevens RJ, Gardner ER, Lee SJ.10 study the irrigation of traumatic wounds with a device consisting of a $20 \mathrm{ml}$ syringe and a $21 \mathrm{~F}$ gauge hypodermic needle. This simple, effective and cheap device can be constructed from items readily available within the emergency department or operating theatre and minimizes exposure to biologically hazardous material during wound irrigation. A study done by Dire and Welsh23 on 531 patients with minor uncomplicated soft tissue lacerations Wounds cleaned With Group A Normal Saline, Group B 1\% Povidone Iodine Group C Pluronic F-68 (ShurClens) they studied the rate of Infection in Group A 13/189 (6.9\%) Group B 8/184 (4.3\%) Group C 9/158 (5.6\%) Isotonic saline has been shown to be as effective as povidone-iodine in reducing infection rates in the human emergency room. No differences were found in infection rates between any type of surgical wounds irrigated with povidone-iodine and those irrigated with normal saline this is because that irrigation method regardless the substance is the corner stay. Griffiths 24 study on 49 patients with chronic wounds. Group A: wounds irrigated with tap water Group B: wounds irrigated with normal saline .Infection rare in Group A 0/23 wounds Group B 3/26 wounds. The insignificant difference also refers to the effectiveness of irrigation method itself. Comparative study by Hollander et.al 25 with concurrent controls 1923 patients with non bite, noncontaminated facial or scalp lacerations, Group A 1090 patients cleaned with saline irrigations, Group B 833 patients cleaned with normal saline and gauze. Rate of Wound infection in Group A $0.9 \%$ in the irrigation group and $1.4 \%$ in the Group B non irrigation group $(\mathrm{P}=0.28$ for difference). Towler J.26 said that Cleansing methods often differ among individual health care providers, institutions and facilities and many times are based on individual experiences and personal preferences, and so he prove the effectiveness of irrigation with tap water or normal sterile saline by 18-19 gauge needle which give 8 psi pressure and how irrigation of wounds removes bacteria and foreign materials, and creates a wound environment optimal for healing. Dean A. Hendrickson,27 compared isotonic normal saline to Hypertonic saline (20\%) he decide that the latter is very effective in reducing bacterial numbers in the surgical wounds by irrigation method. However, it can be traumatic to normal cells as well. Hypertonic saline should be used only in wounds that are obviously infected and not as protective However, the bulk of research shows that povidone iodine is very limited in reducing bacterial numbers in the wound. while isotonic saline reduced bacterial numbers better than povidone iodine. 28

The study by, Lammers RL, Fourre' M, Callaham ML, et.al29 conclude that Povidone iodine was not an effective substitute for wound debridement. The general thought is that Povidone iodine causes necrosis of the underlying tissue leading to more bacterial infection. Consequently, Povidone iodine should only be used around the wound over intact skin, and never in the wound itself.

One of the results of Fernandez R. et al. 30 review about the 
effectiveness of different solutions, techniques and pressure for wound cleansing, he decided that studies undertaken on contaminated wounds, reported a lower infection rate in wounds that were cleansed using povidone iodine. We think that our dependence on calculation of the number of colonies after swapping at the end of each surgery, might be the reason behind the difference between our results and those obtained by Fernandez R. et al, who depended on the clinical features of wound infection appears in subsequent days after surgery, which may depend on other factors, such as the host defense mechanism, presence or absence of nasocomial infection and action of povidone iodine which may need time to get its effect. In his review about wound cleanser Fernandez et al. also provide support for the use of, tap water for routine cleansing of acute and chronic wounds.

\section{Conclusion:}

The rate of wound contamination was significantly reduced after appendectomy when using high pressure irrigation with normal saline, compared with soaking the wound with povidone iodine.

\section{Author contribution}

Hassan Ahmed Hassan: Study conception, critical revision, designs the protocol of the study.

Mohannad Kamel Al-Bermani: selection of study subject, Selection of samples, acquisition of data, writing of manuscript, Interpretation ,collection and analyses of data.

Aws Basheer Abed: support in writing the theses, draftig and manuscript .statistical analysis

\section{References}

1. David J. Leaper, Surgical infection, Bailey\& love, short practice of surgery 26th edition, , part one, chapter five page 53.

2. Winter JM, Cameron JL, and Campbell KA, et al. 1423pancreaticoduodenectomies for pancreatic cancer: a single-institution experienceJ.Gastrointest. Surg. 2006; 10:1199-211.

3. Tang R, Chen HH, Wang YL, et al. Risk factors for surgical siteinfection after elective resection of the colon and rectum: a singlecenter prospective study of 2,809 consecutive patients. Ann Surg 2001;234:181-9.

4. ShahidSadughi. A comparison between traumatic wound infections after irrigating them with tap water and normal saline World Journal of Medical Sciences 2 (1): 58-61, 2007.

5. David E Reichman, and J. A. Greenberg, Reducing Surgical Site Infections: A ReviewObstet Gynecol. 2009 Fall; 2(4): 212-221.

6. Robert Cima, MD et,alColorectal Surgery Surgical Site
Infection Reduction Program: A National Surgical Quality Improvement Program-Driven Multidisciplinary SingleInstitution Experience Journal of the American College of Surgeons Volume 216, Issue 1, January 2013, Pages 23-33

7. Barr, J.E., 1995. Principles of wound cleansing. Ostomy Wound manage, 41: 15S-21S.

8. Jensen, J. and H.T., 1991. The wound healing curve as a practical teaching device. Surg. Gynecol\&Obstetric, 173: 6364.

9. Gruber, R., L. Vistnes and R. Pardoe, 1999.The effect of commonly used antiseptics on wound healing. Plastic Reconstruction Surg., 55: 472-476.

10. Patel CV, Powell L and Wilson S. Surgical Wound Infections. Current Treatment Options in Infectious Diseases 2000; 2: 147-153.

11. Stevens RJ, Gardner ER, Lee SJ A simple, effective and cheap device for the safe irrigation of open traumatic wounds. Emerg Med J. 2009 May; 26(5):354-6.

12. VeerayaPaocharoen MD, ChatchaiMingmalairak MD, AnuchaApisarnthanarak MD, comparison of surgical wound infection after preoperative skin preparation with 4\% chlohexidine and povidone iodine: a prospective randomized trial - J Med Assoc Thai 2009; 92 (7): 898-902 .

13. Weiss EA, Oldham G, Lin M, Foster T, Quinn JV.Water is a safe and effective alternative to sterile normal saline for wound irrigation prior to suturing: BMJ Open.2013 Jan 16;3(1). pii: e001504. doi: 10.1136/bmjopen-2012-001504.

14. Pieper $R$. Kanger $L$. The incidence of acute appendicitis \&appendectomy \& epidemiology study of 971 cases acta. Chir-scand.-1982; 198-45.

15. Beam, J.W., 2006. Wound Cleansing: Water or Saline, J. Athlet. Train., 41: 196-197.

16. Mueller TC, Loos M, Haller B, MihaljevicAL,et al. .Intraoperative wound irrigation to reduce surgical site infections after abdominal surgery: a systematic review and metaanalysis. . Langenbecks Arch Surg. 2015 Feb;400(2):167-81. doi: 10.1007/s00423-015-1279-x. Epub 2015 Feb 14.

17. J. K. Cama, "Recurrentabdominal pain postappendectomy: a rare case," Pacific Health Dialog, vol. 16, no. 2, pp. 78-81, 2010.

18. IrajFeizi, Iraj Poorfarzan, and BitaShahbazzadegan.

Healing Initial of Appendectomy Infection Wounds with Aggressive Washing Method.Iranian Red Crescent Medical Journal. 2013 September; 15(9): 786-8.

19. ComillaSasson, MD, Adam Kennah, MD, Barry Diner, $M D^{\wedge}$. Israeli Journal of Emergency Medicine - Vol. 5, No. 4 Oct 2005

20. Cunliffe, P.J. and T.N. Fawcett, 2002. Wound cleansing: The evidence for the techniques and solutions used. Prof. Nurse, 18: 95-99.

21. Ovington, L.G., 2001. Battling bacteria in wound care. 
Home Healthc Nurse, 19: 622-630.

22. Patel CV, Powell L and Wilson S. Surgical Wound Infections. Current Treatment Options in Infectious Diseases 2000; 2: 147-153.

23. Dire DJ, Welsh AP. A comparison of wound irrigation solutions used in the emergency department. Ann Emerg Med. 1991;19:704-708

24. Griffiths RD, Fernandez RS, Ussia CA. Is tap water a safe alternative to normal saline forwound irrigation in the community setting? J Wound Care 2001; 10: 407

25. Hollander J, Richman PB, Werblud M, Miller T, Huggler $J$, Singer A. Irrigation in facial andscalp lacerations: does it alter outcomes? Ann Emerg Med 1998; 31: 73-7.

26. Towler, J., 2001. Cleansing traumatic wounds with, swabs, water or saline. J. Wound Care, 10: 231-234.

27. Dean A. Hendrickson, DVM, MS, DACVS ,AAEP PROCEEDINGS, What You Should and Should Not Put In or On a Wound, Vol. 61,2015

28. Kucan JO, Robson MC, Heggers JP, et al. Comparison of silver sulfadiazine, povidone-iodine and physiologic saline in the treatment of chronic pressure ulcers. J Am GeriatrSoc 1981;29:232-235

29. Lammers RL, Fourre' M, Callaham ML, et al. Effect of pov-idone-iodine and saline soaking on bacterial counts in acute, traumatic, contaminated wounds. Ann Emerg Med,1990;19:,709-714.

30. Fernandez R, Griffiths R, Ussia C. The Effectiveness of Solutions, Techniques and Pressurein Wound Cleansing: a Systematic Review. Adelaide: Joanna Briggs Institute, 2001. 